\title{
Influence of nutritional intervention on children with type 1 diabetes mellitus and DPP-4 in serum
}

\author{
YAN-JUN DONG ${ }^{1}$, LI-JUAN LIU ${ }^{1}$, HUI-MING CHEN ${ }^{2}$, JING SUN $^{2}$, MING-HUA XIAO $^{2}$ and JIN-HUI WU ${ }^{2}$ \\ ${ }^{1}$ Department of Laboratory Medicine, People's Hospital of Rizhao, Rizhao, Shandong 261000; ${ }^{2}$ Department of Clinical \\ Nutrition, Guangzhou Women and Children's Medical Center, Guangzhou, Guangdong 510623, P.R. China
}

Received September 21, 2016; Accepted January 16, 2017

DOI: $10.3892 /$ etm.2017.4575

\begin{abstract}
The level of dipeptidyl peptidase-4 (DPP-4) of children with type 1 diabetes mellitus (T1DM) was observed to evaluate the improvement in function of the nutritional intervention. In total, 132 children with T1DM (T1DM group) and 132 healthy children (NC group) based on physical examination admitted to our hospital from September 2014 to June 2015 and were studied. General data of the two groups as well as the concentration of DPP-4 and various biochemical criterion in peripheral serum were collected and analyzed. Compared with NC group, DPP-4 level of T1DM group was obviously increased $(\mathrm{P}<0.05)$; after insulin treatment, the serum level of DPP-4 of T1DM group decreased, but was still significantly higher than that of $\mathrm{NC}$ group $(\mathrm{P}<0.05)$. After 3 months of clinical nutritional intervention, body mass index (BMI) of children with T1DM was significantly reduced compared with data before the treatment $(\mathrm{P}<0.05)$. However, the level of DPP-4 appeared unchanged ( $>0.05)$. Pearson's correlation analysis showed that the level of DPP-4 had a positive correlation with diabetic duration, BMI and gamma $(\gamma)$-glutamyl transpeptidase for children suffering TIDM $(\mathrm{P}<0.05)$. Multiple linear regression analysis showed that BMI may be a factor influencing DPP-4 level in serum of T1DM children. In conclusion, the level of DPP-4 in serum increased, and insulin treatment was able to decrease DPP-4 level in T1DM children. However, clinical nutritional intervention could not improve the level of DPP-4 and BMI may be an influental factor of the DPP-4 level.
\end{abstract}

\section{Introduction}

Type 1 diabetes mellitus (T1DM) of children is a congenital and chronical metabolic disease, which is caused by the

Correspondence to: Dr Li-Juan Liu, Department of Laboratory Medicine, People's Hospital of Rizhao, 126 Tai'an Road, Rizhao, Shandong 261000, P.R. China

E-mail: benmt_927759@163.com

*Contributed equally

Key words: type 1 diabetes mellitus, dipeptidyl peptidase-4, nutritional intervention absolute shortage of insulin secretion. All patients with T1DM depend on insulin treatment. Unfortunately, the treatment that is not on time may cause the death of child patients $(1,2)$. Dipeptidyl peptidase-4 (DPP-4) is a kind of biology active enzyme, and the substrate glucagon-like peptide-1 (GLP-1) which actes by DPP-4 has the function of regulating blood sugar in human body $(3,4)$. In clinic, DPP-4 inhibitor is often applied to cure T2DM, but the research on T1DM is, however, sparse (5-8). Therefore, based on previous studies, our study compared DPP-4 level in healthy children and those suffering T1DM before and after insulin treatment, under clinical nutritional intervention. Characteristic changes of DPP-4 level were observed in order to provide help for T1DM treatment.

\section{Patients and methods}

General data. The related content and methods of our study was approved by Ethics Department of People's Hospital of Rizhao. The family of patients in the two groups signed the informed consent after they were told intervention-related situation and state of the illness.

One hundred thirty-two children suffering T1DM (T1DM group) and 132 healthy children (NC group) admitted to our hospital from September 2014 to June 2015 were selected as research subjects. T1DM group contained 72 males and 60 females, with age of 1.5-10.0 years and an average age of $3.75 \pm 0.85$ years, whose course of disease was 3 months to 9 years, with average course of disease of $1.24 \pm 0.31$ years. The child patients in the group met the child T1DM-related diagnostic criteria, excluding the patients with complicated malignant tumors, various organic pathologic changes and previous hypoglycemia. The NC group contained 57 males and 75 females, with age of 0.5-14 years and average age of $4.65 \pm 1.75$ years. The results of physical examination did not show fasting blood-glucose (FBG) increase and/or other organic or functional disease. This study was approved by the Ethics Committee of People's Hospital of Rizhao. Signed written informed consents were obtained from guardians of all participants before the study.

Methods. The general data of the children were collected, including gender, age, duration of diabetes, and blood pressure, height, weight and body mass index (BMI) were measured. Portable glucometer (Medtronic, Inc., Minneapolis, MN, USA) 
Table I. Analysis of clinical features of patients in two groups (mean $\pm \mathrm{SD})$.

\begin{tabular}{|c|c|c|c|c|c|c|c|c|}
\hline Groups & Cases $(\mathrm{M} / \mathrm{F})$ & Age (years) & $\begin{array}{c}\text { Duration of } \\
\text { diabetes (months) }\end{array}$ & $\begin{array}{c}\text { SBP } \\
(\mathrm{mmHg})\end{array}$ & $\begin{array}{c}\text { DBP } \\
(\mathrm{mmHg})\end{array}$ & $\begin{array}{c}\text { BMI } \\
\left(\mathrm{kg} / \mathrm{m}^{2}\right)\end{array}$ & $\begin{array}{l}\text { AST } \\
(\mathrm{U} / 1)\end{array}$ & $\begin{array}{l}\text { ALT } \\
(\mathrm{U} / 1)\end{array}$ \\
\hline $\mathrm{NC}$ & $132(57 / 75)$ & $3.65 \pm 0.87$ & - & $118.5 \pm 30.5$ & $70.4 \pm 22.8$ & $19.7 \pm 2.4$ & $17.2 \pm 2.1$ & $12.7 \pm 3.6$ \\
\hline T1DM & $132(72 / 60)$ & $3.27 \pm 1.24$ & $10.78 \pm 6.51$ & $102.4 \pm 23.7$ & $67.4 \pm 34.7$ & $23.6 \pm 1.8$ & $16.5 \pm 2.4$ & $3.2 \pm 4.9$ \\
\hline t-test & - & 0.68 & - & 0.17 & 0.45 & 1.32 & 0.78 & 0.44 \\
\hline P-value & - & $>0.05$ & - & $>0.05$ & $>0.05$ & $<0.05$ & $>0.05$ & $>0.05$ \\
\hline Groups & $\begin{array}{l}\text { GGT } \\
(\mathrm{U} / \mathrm{l})\end{array}$ & $\begin{array}{c}\text { FPG } \\
(\mathrm{mmol} / \mathrm{l})\end{array}$ & $\mathrm{HbA} 1 \mathrm{C}(\%)$ & $\begin{array}{c}\mathrm{TC} \\
(\mathrm{mmol} / \mathrm{l})\end{array}$ & $\begin{array}{l}\text { HDL-C } \\
(\mathrm{mmol} / \mathrm{l})\end{array}$ & $\begin{array}{c}\text { LDL-C } \\
(\mathrm{mmol} / \mathrm{l})\end{array}$ & $\begin{array}{c}\text { DPP-4 } \\
(\mathrm{mmol} / \mathrm{l})\end{array}$ & \\
\hline $\mathrm{NC}$ & $18.6 \pm 2.2$ & $4.37 \pm 0.85$ & $4.70 \pm 0.43$ & $185.4 \pm 20.6$ & $67.5 \pm 13.5$ & $98.5 \pm 10.2$ & $2.63 \pm 0.38$ & \\
\hline T1DM & $17.3 \pm 3.6$ & $8.24 \pm 3.36$ & $7.82 \pm 1.03$ & $177.3 \pm 21.2$ & $68.4 \pm 11.8$ & $102.3 \pm 21.6$ & $5.83 \pm 2.31$ & \\
\hline t-test & 0.67 & 1.79 & 1.56 & 0.75 & 0.52 & 0.63 & 2.35 & \\
\hline P-value & $>0.05$ & $<0.05$ & $<0.05$ & $>0.05$ & $>0.05$ & $>0.05$ & $<0.05$ & \\
\hline
\end{tabular}

NC, normal children group; T1DM, type 1 diabetes mellitus; M, male; F, female; BMI, body mass index; DDP-4, dipeptidyl peptidase-4.

Table II. Comparison of FPG and DPP-4 level of T1DM group before and after insulin treatment (mean $\pm \mathrm{SD})$.

\begin{tabular}{lccc}
\hline Groups & Cases (n) & $\begin{array}{c}\text { FPG } \\
(\mathrm{mmol} / \mathrm{l})\end{array}$ & $\begin{array}{c}\text { DPP-4 } \\
(\mathrm{mmol} / \mathrm{l})\end{array}$ \\
\hline $\mathrm{NC}$ & 132 & $4.28 \pm 0.49$ & $2.72 \pm 0.58$ \\
T1DM & & & \\
Before treatment & 132 & $8.24 \pm 3.36$ & $5.83 \pm 2.31$ \\
After treatment & 132 & $5.37 \pm 0.76$ & $4.24 \pm 1.28$ \\
F-value & & 1.20 & 2.73 \\
P-value & & $<0.05$ & $<0.05$ \\
\hline
\end{tabular}

DPP-4, dipeptidyl peptidase-4; T1DM, type 1 diabetes mellitus; $\mathrm{NC}$, normal children group.

was used to detect FPG. Peripheral venous blood of $4 \mathrm{ml}$ was extracted from the patients, then measured by DPP-4 detection kit, and the serum concentration of DPP-4 was recorded. The biochemical indexes such as blood fat and transaminase were tested by Roche Modular Fully Automatic Biochemical Analyzer (Roche Diagnostics, Indianapolis, IN, USA). Based on the insulin intervention treatment, 3 months of medical nutritional intervention strategy was carried out. Medical nutritional therapy and education group trained the parents (the daily caregiver of child patients), to teach them carbohydrate calculation method, food exchange portion and glucose resultant index, lasting for 3 days and $2 \mathrm{~h}$ per day. During everyday training, the nutritionist demonstrated the choice, collocation and cooking of meal on site. After all parents in research group finished the training, they provided meals for the children according to the requirement and measured blood glucose at least 7 times per day.

Statistical analysis. Software SPSS 20.0 (IBM SPSS, Armonk, NY, USA) was used to analyze data. $\mathrm{P}<0.05$ was considered to indicate a statistically significant difference. Experiment data that conformed to normal distribution was presented by mean \pm standard deviation (mean $\pm \mathrm{SD}$ ), which was tested by t-test or one-way analysis of variance. DPP-4 level and clinical characteristic data were processed by Pearson's correlation analysis and multiple linear regression analysis.

\section{Results}

Comparison of clinical characteristics between two groups. Compared with NC group, BMI, FPG and HbA1c from T1DM group were obviously higher than those of control group $(\mathrm{P}<0.01)$. Level of DPP-4 in T1DM serum was also significantly higher than in NC group $(\mathrm{P}<0.05)$ (Table I).

Comparison of FPG and DPP-4 level of T1DM group before and after treatment. Insulin was applied in T1DM group and FPG was recorded during treatment every day. It was found that, compared with the state before the treatment, FPG level of T1DM group decreased after the treatment. concomitantly, the level of DPP-4 increased, but was still higher than that in $\mathrm{NC}$ group $(\mathrm{P}<0.05)$ (Table II).

Influence of medical nutritional intervention on the level of DPP-4 in children suffering T1DM. After receiving medical nutritional intervention treatment, FPG, BMI, LDL-L and TG level in children suffering T1DM decreased $(\mathrm{P}<0.05)$, while the level of DPP-4 did not change obviously ( $\mathrm{P}>0.05)$ (Table III).

Correlation analysis between DPP-4 level in serum and other factors of children patients with T1DM. Pearson's correlation analysis showed that DPP-4 level had a positive correlation with diabetic duration, BMI and gamma $(\gamma)$-glutamyl transpeptidase (GGT) for the children with TIDM $(\mathrm{P}<0.05)$ (Table IV). DPP-4 level was taken as a dependent variable, and gender, age, duration of diabetes, SBP, DBP and other indexes were taken as independent variable, to analyze by multiple linear regression analysis. Multiple linear regression analysis showed 
Table III. Influence of nutrition intervention on BMI and DPP-4 level of children with T1DM (mean \pm SD).

\begin{tabular}{lcccccc}
\hline Groups & Cases $(\mathrm{n})$ & FPG $(\mathrm{mmol} / \mathrm{l})$ & BMI $\left(\mathrm{kg} / \mathrm{m}^{2}\right)$ & LDL-C $(\mathrm{mmol} / \mathrm{l})$ & TC $(\mathrm{mmol} / \mathrm{l})$ & DPP-4 (mmol/l) \\
\hline Before & 132 & $8.24 \pm 3.36$ & $23.6 \pm 1.8$ & $102.3 \pm 21.6$ & $185.4 \pm 20.6$ & $5.83 \pm 2.31$ \\
After & 132 & $7.27 \pm 1.36$ & $20.7 \pm 3.3$ & $87.4 \pm 12.6$ & $157.3 \pm 20.8$ & $5.74 \pm 1.66$ \\
F-value & - & 1.20 & 1.74 & 2.37 & 4.38 & 0.46 \\
P-value & - & $<0.05$ & $<0.05$ & $<0.05$ & $<0.05$ & $>0.05$ \\
\hline
\end{tabular}

BMI, body mass index; DPP-4, dipeptidyl peptidase-4; T1DM, type 1 diabetes mellitus.

Table IV. Correlation analysis between DPP-4 and clinical detection index (r).

\begin{tabular}{|c|c|c|c|c|c|c|c|c|c|c|}
\hline Index & Gender & $\begin{array}{c}\text { Age } \\
\text { (years) }\end{array}$ & $\begin{array}{c}\text { Duration of } \\
\text { diabetes (months) }\end{array}$ & $\begin{array}{c}\text { SBP } \\
(\mathrm{mmHg})\end{array}$ & $\begin{array}{c}\text { DBP } \\
(\mathrm{mmHg})\end{array}$ & $\begin{array}{l}\text { AST } \\
(\mathrm{U} / 1)\end{array}$ & $\begin{array}{l}\text { ALT } \\
(\mathrm{U} / 1)\end{array}$ & $\begin{array}{l}\log \mathrm{GGT} \\
(\mathrm{U} / 1)\end{array}$ & $\begin{array}{c}\text { FPG } \\
(\mathrm{mmol} / \mathrm{l})\end{array}$ & $\begin{array}{c}\text { BMI } \\
\left(\mathrm{kg} / \mathrm{m}^{2}\right)\end{array}$ \\
\hline \multicolumn{11}{|l|}{ DPP-4 } \\
\hline $\mathrm{r}$ & 0.02 & 0.35 & 0.17 & 0.16 & 0.28 & 0.24 & 0.15 & 0.06 & 0.38 & 0.14 \\
\hline P-value & $>0.05$ & $>0.05$ & $<0.05$ & $>0.05$ & $>0.05$ & $>0.05$ & $>0.05$ & $<0.05$ & $>0.05$ & $<0.05$ \\
\hline
\end{tabular}

DDP-4, dipeptidyl peptidase-4; BMI, body mass index.

Table V. Multiple linear regression analysis of DPP-4 level of factors for child patients with T1DM.

$(95 \% \mathrm{CI})$

\begin{tabular}{lccccccc}
\cline { 6 - 8 } Variables & $\beta$ & $\mathrm{SE}$ & $\beta^{\prime}$ & $\mathrm{t}$ & P-value & Upper limit & Lower limit \\
\hline Duration of diabetes & 0.531 & 0.14 & 0.764 & 0.412 & $>0.05$ & 0.26 & 0.81 \\
logGGT & 0.581 & 0.10 & 0.642 & 0.652 & $>0.05$ & 0.39 & 0.78 \\
BMI & 0.768 & 0.08 & 0.871 & 0.981 & $<0.05$ & 0.61 & 0.92 \\
\hline
\end{tabular}

DDP-4, dipeptidyl peptidase-4; T1DM, type 1 diabetes mellitus; BMI, body mass index.

that BMI may be a factor influencing the level of DPP-4 in the serum of T1DM children $(\mathrm{P}<0.05)($ Table $\mathrm{V})$.

\section{Discussion}

From previous studies of T2DM, it was found that DPP-4 is an intestinal enzyme, also named as ferment, playing a role in the small intestine and that was involved in the decomposition of protein within human body (9-11). Among them, GLP-1, a protein that is decomposed by DPP-4, is also called insulinotropic harmonic polypeptide-1, which is a hormone material secreted by intestinal cells. The physiological function of GLP-1 is complicated. It is thought to reduce blood glucose by stimulating insulin, controlling glucagon, inhibiting gastric emptying and promoting islet cell regeneration (12-14). GLP-1 can also secrete glucagon and the decomposition of hepatic glycogen by reducing pancreas cell function to promote blood glucose into liver and skeletal muscle, thereby compounding glycogen that is reserved for blood glucose regulation $(15,16)$. DPP-4 inhibitor has been applied to clinic for T2DM, but for the patients with
T1DM, we have not found a favorable ancillary drug (17). From the comparison of DPP-4 level between child patients and normal children, it was found that DPP-4 level of child patients with T1DM significantly increased, according to the feature of insulin absolute shortage for T1DM. In addition, after the treatment with insulin, the DPP-4 level of children with T1DM decreased obviously, so we speculated that it may depend on the function characteristics of DPP-4, which mainly included (18-20): i) The function of regulating pancreas $\beta$ cells and secrete insulin; ii) the unique insulin dependence feature of secreting and regulating blood glucose when glucose is increasing in human body. Therefore, it has a defensive function for pancreas $\beta$ cells, which can significantly reduce the apoptosis of pancreas $\beta$ cells and prolong the life span of islet cells (8). Due to the insulin dependence feature of GLP-1, insulin absolute shortage can lead to the increase of GLP-1 level for child patients with T1DM, then DPP-4 level will increase as well. In a previous study conducted by Lamers et al (9) reported that among the patients with T1DM in Japan, DPP-4 level in serum was higher than that of healthy people. So hoping to find a substitution or partial substitution 
of insulin to cure T1DM. Nevertheless, for the children with T1DM, the research of this kind still lack sufficient evidence.

Our study also found that DPP-4 level had a positive correlation with duration of diabetes, BMI and GGT among the child patients with diabetes; multiple linear regression analysis showed that DPP-4 was influenced by BMI mostly. By this token, for the child patients with T1DM, it is necessary to adopt targeted treatment strategy of nutrition intervention, so as to improve DPP-4 level by controlling BMI. The study of DPP-4 originated from 30- or 40-year age groups. The scientists discovered incretin in the first place, with a releasing feature of secreting by enteroendocrine cells in small intestine after eating. Moreover, one study (10) pointed out a case report of combination of insulin and DPP-4 inhibitor during the treatment of T1DM (10). This type of research is absent among Han ethnicity child patients with T1DM. From our results, in previous studies, DPP-4 level was influenced by the interactions of many factors so that the relation among these confounding factors was not explained clearly. The present study analyzed the relation between these confounding factors and DPP-4 by multiple linear regression analysis and found BMI as the breakthrough. Therefore, we hold that reasonable nutrition ingestion and control can improve the dietary nutrition of child patients, which is of great benefit for the control of T1DM and pancreas islet function.

Furthermore, we designed a clinical experiment of nutrition intervention, and it was found that after 3 months of clinical nutritional intervention, BMI of children with T1DM significantly improved $(\mathrm{P}<0.05)$; however, DPP-4 level did not appear obviously changed compared with that of prior treatment $(\mathrm{P}>0.05)$. Based on this result, we concluded that nutrition intervention could not improve insulin level in human body directly and could not directly improve DPP-4 level either. However, BMI may be one of the important factors influencing DPP-4 level, but the influence and time require further research.

In conclusion, DPP-4 level increased obviously among the child patients with T1DM. The aim of this study was to reach an accurate understanding of DPP-4 level in serum of Han ethnicity children with T1DM. Therefore, we can adopt nutritional intervention with pertinence to improve the condition of the child patients by controlling BMI.

\section{References}

1. Kim C, Karvonen-Gutierrez C, Kong S, Arends V, Steffes M, McConnell DS, Randolph JF Jr and Harlow SD: Antimüllerian hormone among women with and without type 1 diabetes: the Epidemiology of Diabetes Interventions and Complications Study and the Michigan Bone Health and Metabolism Study. Fertil Steril: Jul 28, 2016 (Epub ahead of print).

2. Tully C, Aronow L, Mackey E and Streisand R: Physical activity in youth with type 1 diabetes: a review. Curr Diab Rep 16: 85, 2016.

3. Hallford P, Clair DS, Halley L, Mustard C and Wei J: A study of type-1 diabetes associated autoantibodies in schizophrenia. Schizophr Res 176: 186-190, 2016.
4. Nasir H and Narasimhan S: Type 1 diabetes: the need for culture-appropriate nutritional information for carbohydrate counting. Lancet Diabetes Endocrinol 4: 812, 2016.

5. Takashima S, Fujita H, Fujishima H, Shimizu T, Sato T, Morii T, Tsukiyama K, Narita T, Takahashi T, Drucker DJ, et al: Stromal cell-derived factor- 1 is upregulated by dipeptidyl peptidase- 4 inhibition and has protective roles in progressive diabetic nephropathy. Kidney Int 90: 783-796, 2016.

6. Jojima T, Tomotsune T, Iijima T, Akimoto K, Suzuki K and Aso Y: Empagliflozin (an SGLT2 inhibitor), alone or in combination with linagliptin (a DPP-4 inhibitor), prevents steatohepatitis in a novel mouse model of non-alcoholic steatohepatitis and diabetes. Diabetol Metab Syndr 8: 45, 2016.

7. Horowitz M, Wu T, Deane AM, Jones KL and Rayner CK: DPP-4 inhibition and the known unknown. Diabetes 65: 2124-2126, 2016.

8. Itou M, Kawaguchi T, Taniguchi E and Sata M: Dipeptidyl peptidase-4: a key player in chronic liver disease. World J Gastroenterol 19: 2298-2306, 2013.

9. Lamers D, Famulla S, Wronkowitz N, Hartwig S, Lehr S, Ouwens DM, Eckardt K, Kaufman JM, Ryden M, Müller S, et al: Dipeptidyl peptidase 4 is a novel adipokine potentially linking obesity to the metabolic syndrome. Diabetes 60: 1917-1925, 2011.

10. Karagiannis T, Paschos P, Paletas K, Matthews DR and Tsapas A: Dipeptidyl peptidase-4 inhibitors for treatment of type 2 diabetes mellitus in the clinical setting: systematic review and meta-analysis. BMJ 344: e1369, 2012.

11. Ishibashi Y, Matsui T, Maeda S, Higashimoto Y and Yamagishi S: Advanced glycation end products evoke endothelial cell damage by stimulating soluble dipeptidyl peptidase- 4 production and its interaction with mannose 6-phosphate/insulin-like growth factor II receptor. Cardiovasc Diabetol 12: 125, 2013.

12. Osawa S, Kawamori D, Katakami N, Takahara M, Sakamoto F, Katsura T, Yasuda T, Kaneto H, Matsuhisa M, Matsuoka TA, et al: Significant elevation of serum dipeptidyl peptidase-4 activity in young-adult type 1 diabetes. Diabetes Res Clin Pract 113: 135-142, 2016.

13. Chen C, Yu Q, Zhang S, Yang P and Wang CY: Assessing the efficacy and safety of combined DPP-4 inhibitor and insulin treatment in patients with type 2 diabetes: a meta-analysis. Int J Clin Exp Pathol 8: 14141-14150, 2015.

14. Mannucci E, Mosenzon O and Avogaro A: Analyses of results from cardiovascular safety trials with DPP-4 inhibitors: cardiovascular outcomes, predefined safety outcomes, and pooled analysis and meta-analysis. Diabetes Care 39 (Suppl 2): S196-S204, 2016.

15. Schnapp G, Klein T, Hoevels Y, Bakker RA and Nar H: Comparative analysis of binding kinetics and thermodynamics of dipeptidyl peptidase-4 inhibitors and their relationship to structure. J Med Chem 59: 7466-7477, 2016.

16. Kamiya H: A systematic review of the benefits and harms of dipeptidyl peptidase-4 inhibitor for chronic kidney disease. Hemodial Int: Jul 19, 2016 (Epub ahead of print).

17. Scheen AJ: DPP-4 inhibitor plus SGLT-2 inhibitor as combination therapy for type 2 diabetes: from rationale to clinical aspects. Expert Opin Drug Metab Toxicol 29: 1-11, 2016.

18. Katsuyama H, Fukunaga T, Hamasaki H, Adachi H, Moriyama S, Kawaguchi A, Mishima S, Sako A and Yanai H: The influences of withdrawal and daily dose reduction of pioglitazone on metabolic parameters in patients with type 2 diabetes: a retrospective longitudinal observational study. J Clin Med Res 8: 585-590, 2016.

19. Barry AR and Turgeon RD: DPP-4 inhibitors: the Seinfeld of oral antihyperglycemics. Can J Hosp Pharm 69: 253-254, 2016.

20. Li S, Xu H, Cui S, Wu F, Zhang Y, Su M, Gong Y, Qiu S, Jiao Q, Qin C, et al: Discovery and rational design of natural-product-derived 2-phenyl-3,4-dihydro- $2 H$-benzo $[f]$ chromen-3-amine analogs as novel and potent dipeptidyl peptidase 4 (DPP-4) inhibitors for the treatment of type 2 diabetes. J Med Chem 59: 6772-6790, 2016. 